\title{
Al-based Amorphous Alloys: Glass-forming Ability, Crystallization Behavior and Effects of Minor Alloying Additions
}

\author{
Y.Shen ${ }^{1}$ J.H. Perepezko ${ }^{1, \#}$ \\ ${ }^{1}$ University of Wisconsin-Madison, Department of Materials Science and Engineering, \\ 1509 University Ave., Madison, WI, 53706, USA \\ ${ }^{\#}$ Corresponding author. E-mail address: perepezk@engr.wisc.edu, Tel: +1 6082631678
}

Keywords: Primary Crystallization; Glass Forming Ability; Metallic glasses

\begin{abstract}
The main recent advances in Al-based amorphous alloys are discussed in three areas: crystallization behavior, glass-forming ability and minor alloying effects. First, as a brief introduction, the special features and structure-property relationships are presented for the Albased amorphous alloys. The different models for the nucleation behaviors, such as phase separation model and the quenched-in nuclei model, are compared and evaluated. In addition, an overview is given for the effects of minor alloying additions on glass-forming ability (GFA) and the crystallization behavior in terms of the reported structural, thermodynamic, kinetic factors.
\end{abstract}

\section{Introduction}

Al-based metallic glasses ( $\mathrm{Al}>80$ at.\%) with the rare-earth metals (RE) and transition metals (TM) additions were first discovered in the 1980s [1,2]. There are several special features for Al-based metallic glass. First, most of the Al-based metallic glasses are marginal glass formers, which are different from the bulk metallic glasses due to the requirement for higher critical cooling rates $\left(10^{5}-10^{6} \mathrm{~K} / \mathrm{s}\right)$ to avoid crystallization. Therefore, rapid solidification techniques such as melt spinning have been mainly used to prepare Al-based metallic glasses. Other synthesizing methods include cold rolling [3] and ball milling [4]. Secondly, most of the Al-based metallic glasses exhibit no obvious glass transition signal $\mathrm{T}_{\mathrm{g}}$ nor the supercooled liquid region in the differential scanning calorimetry (DSC) continuous heating trace because the onset 
of the primary crystallization peak $T_{x}$ nearly coincides with the glass transition[5]. Other approaches such as the temperature-modulated DSC (TMDSC) and dynamic mechanical analysis (DMA) can be applied to measure $T_{g}$ more precisely [5-8] and a hold below $T_{x}$ can reveal the $T_{g}$ signal $[9,10]$. Thirdly, a typical continuous DSC trace for most of the Al-based metallic glass shows a shallow primary crystallization peak for $\mathrm{Al}_{\mathrm{fcc}}$ followed by sharp secondary crystallization peaks of intermetallic phases (Fig. 1 (a)). The separation between the primary and secondary crystallization of more than $50{ }^{\circ} \mathrm{C}$ signifies a metastable $\mathrm{Al}$ and glass equilibrium. This is somewhat unexpected because within the hypereutectic glass forming composition range, the thermodynamic driving free energy for crystallization favors the Al rich intermetallic phase over the $\mathrm{Al}_{\text {fcc }}$.(Fig. 1 (b)) [11] Thus, the kinetic selection of $\mathrm{Al}$ as the primary crystallization phase must be promoted by a nucleation catalyst. A change in composition may lead to a change of the crystallization pathway [12-14]. Tsai et al. conclude that only when the values of the atomic size ratio $\lambda$ and the Al content fall into the range of $0.04-0.07$ and 82-90 at.\% respectively, a dispersion of nanoscale fcc-Al in the amorphous matrix could be obtained in Al$\mathrm{Ni}-\mathrm{Ce}$ amorphous alloys [15]. Moreover, a high number density of primary crystallized $\mathrm{Al}_{\mathrm{fcc}}$ nano-particles $\left(10^{21}-10^{24} \mathrm{~m}^{-3}, 5-50\right.$ in diameter) dispersed in the amorphous matrix. (Fig. 1 (c)) can be generated by either annealing the as-quenched amorphous Al alloys under suitable experimental conditions [5] or by the direct solidification of the molten alloy at a cooling rate lower than the critical cooling rate $[16,17]$. In addition, the Williamson and Hall analysis on $\mathrm{XRD}$ (X-ray diffraction) traces indicates that the $\mathrm{Al}$ nanocrystals are under an elastic compressive stress [18].

The Al-based metallic glasses show great potential in applications requiring high corrosion resistance, high wear resistance, high strength, and relatively low density. The specific strength can be further increased to levels beyond that of many common steels through partial devitrification [19-21]. For example, Kan et al. have obtained a novel Al-based composite material with an ultrahigh strength of about $1.34 \mathrm{GPa}$ through the controlled annealing treatment of an Al-Ni-Y-Co-La amorphous alloy [22]. Inoue et al. have prepared novel Al-based alloys with the high rotating beam fatigue strength above $400 \mathrm{MPa}$ at $10^{7}$ cycles and high corrosion resistance below $20 \mathrm{~mm}$ /year in $0.25 \mathrm{M} \mathrm{NaOH}$ aqueous solution at $293 \mathrm{~K}$ [23]. Also, both the mechanical and corrosion properties of the partially crystallized Al-based metallic glass are closely related with the microstructure. In the $\mathrm{Al}_{86} \mathrm{Ni}_{6} \mathrm{Y}_{6} \mathrm{Ce}_{2}$ alloy, the formation of nano-sized $\alpha$ - 
$\mathrm{Al}$ and fine hard $\mathrm{Al}_{3} \mathrm{Ni}$ intermetallic compounds at the first and second crystallization stages is favored in the hardening effect because the residual amorphous matrix is hardened from solute enrichment and there is a precipitation hardening effect. However, the coarsening of the particles and formation of a weak intermetallic compound $\mathrm{Al}_{11} \mathrm{Y}_{3}$ at the final stage lowers the hardness [24] For the Al-Ni-Ce alloy, the high pitting corrosion resistance of the amorphous alloy was not deteriorated by the nanocrystalline $\alpha$-Al precipitation, whereas the pitting potential was decreased due to the formation of the intermetallic phases $\mathrm{Al}_{3} \mathrm{Ni}$ and $\mathrm{Al}_{11} \mathrm{Ce}_{3}$ [25].

The unique features of the Al-based metallic glasses, such as the high critical cooling rate, the unclear $\mathrm{T}_{\mathrm{g}}$ and the high number density of $\mathrm{Al}_{\mathrm{fcc}}$ nanoparticles, suggest a high nucleation rate and a sluggish growth. The understanding of the crystallization behavior of the Al-based metallic glasses is important in order to control the microstructure for optimizing the material properties and is considered in the initial part of the review. The poor glass forming ability is a big challenge and has limited the applications of the Al based amorphous alloys. As a result, there has been a focused effort that aims to overcome this bottleneck problem of the relatively low glass forming ability (GFA). Both the crystallization behaviors and the GFA of the Al-based metallic glasses are very sensitive to minor element doping and the underlying mechanism has been considered in terms of the structural, thermodynamic and kinetic factors. Within the available coverage, the discussion of recent advances will focus on the main highlights for GFA, crystallization and minor alloying effects.

\section{Crystallization behavior}

In most cases, crystallization in Al-based amorphous alloys is induced by thermal treatment. However, severe plastic deformation (SPD), such as rolling, tension and torsion, is an alternative approach to stimulate crystallization. From in-situ tensile straining in the TEM on amorphous $\mathrm{Al}_{88} \mathrm{Y}_{7} \mathrm{Fe}_{5}$ [26] and the multiple rolling on Al-Ni-Co-Gd-Si [27], nanocrystals were observed to form preferentially in shear bands presumably due to the enhanced atomic mobility from the marked increase in the excess volume inside the shear bands. However, observations following the high pressure torsion applied to an $\mathrm{Al}_{90} \mathrm{Y}_{10}$ amorphous alloy indicated that there was no correlation between the location of nanocrystals and the position of shear bands [28] and Jiang et al. reported that in the tensile region of the amorphous Al-Fe-Gd sample under bending, nanocrystals formed only at the fracture surface, which was likely to be due to the adiabatic 
heating [29]. Lastly, other examples including the corrosion induced [30] and ion irradiation induced crystallizations [31] have been reported for $\mathrm{Al}$ based metallic glasses.

For thermally activated crystallization, the Johnson-Mehl-Avrami (JMA) relation (Eq. 1) and the Kissinger analysis (Eq. 2) are two convenient and widely used approaches to describe the crystallization kinetics.

$\alpha(t)=1-\exp \left\{-[k(t-\tau)]^{n}\right\}$

Eq. 1

$\ln \left(\frac{T^{2}}{\Phi}\right)=\left(\frac{E}{R T}\right)+$ constant

where $\alpha$ is the crystallization fraction, $t$ is annealing time, $\tau$ is the incubation time, $k$ is the effective overall reaction rate constant, which reflects both the nucleation frequency and the crystal growth rate, $\mathrm{n}$ is the Avrami exponent, which is a number dependent on the nucleation and growth process, $\Phi$ is the heating rate, $T$ is the specific temperature, $R$ is the gas constant and $\mathrm{E}$ is the activation energy for a specific reaction. For instance, the Avrami exponent, n, obtained for the primary crystallization of an $\mathrm{Al}_{90} \mathrm{~Tb}_{10}$ amorphous alloy was reported to be 2.5, which indicates a three dimensional diffusional growth with constant nucleation rate [32]. However, the activation energies from the Kissinger analysis of the primary crystallization in a number of different amorphous $\mathrm{Al}$ alloys have been determined to range from $146 \mathrm{~kJ} / \mathrm{mol}$ to $317 \mathrm{~kJ} / \mathrm{mol}$ [33] and with the Avrami exponent ranging from 1.6 to $5.0[33,34]$. Both $\mathrm{E}$ and $\mathrm{n}$ depend strongly on composition [33]. Though the JMA equation and the Kissinger analyses are useful for a general characterization of the thermal stability, the large variations in the $\mathrm{E}$ and $\mathrm{n}$ values for primary crystallization in different amorphous $\mathrm{Al}$ alloys indicate that insight into the detailed physical mechanisms is not readily obtained from these methods.

In another approach, the details of the nucleation statistics can be obtained from direct TEM observation to determine the $\mathrm{Al}$ nanocrystal size distribution as a function of isothermal annealing time and temperature $[10,11]$. This allows for a direct measurement of the steady state nucleation rate and reveals the importance of transient behavior associated with a delay time $\tau$. A typical crystal number density vs. annealing time plot obtained by counting particle numbers on the TEM images shows three stage: the transient stage, steady state nucleation stage and saturation stage. (Fig. 2). Similar plots with three stages could also be obtained by integrating the 
isothermal DSC scan [32] and the NMR spectra [33]. In the final stage, due to the exhaustion of nucleation sites, soft impingement and hard impingement, the crystal number density saturates. The nucleation rate is given by

$$
J(t)=J_{S S} \exp \left(-\frac{\tau}{t}\right)=\left[\rho \beta Z \exp \left(-\frac{\Delta G^{*}}{k T}\right)\right] \exp \left(-\frac{\tau}{t}\right)
$$

where $J_{\mathrm{ss}}$ is the steady state nucleation rate, $\tau$ is the delay time, $\rho$ is the nucleation site density, $\beta$ is the attachment frequency, $\mathrm{Z}$ is the Zeldovich factor that is of the order of $0.1, \mathrm{k}$ is the Boltzmann constant and $\Delta G^{*}$ is the nucleation barrier. The evaluation of $\Delta \mathrm{G}^{*}$ depends on the model for the nucleus and has been discussed in detail for homogeneous nucleation[35]. For the medium range order (MRO) catalyzed heterogeneous nucleation shown in Fig. 3, $\Delta \mathrm{G}^{*}$ is given by

$$
\begin{aligned}
& \Delta G^{*}=\Delta G\left(r=r^{*}\right) \\
& =\frac{4 \pi}{3}\left(\mathrm{r}^{*}-r_{o}^{3}\right) \Delta G_{V}+\left[4 \pi r_{o}^{2}\left(\sigma_{\mathrm{MRO} / \text { rystal }}-\sigma_{\mathrm{MRO} / \text { glass }}\right)+4 \pi r^{2} \sigma_{\text {crystal glass }}\right]
\end{aligned}
$$

where $r_{o}$ is the MRO radius, $\Delta G_{v}$ is the volume free energy, $\sigma_{\text {MRO/crystal }}$ is the MRO/crystal interfacial energy, $\sigma_{M R O / \text { glass }}$ is the MRO/glass interfacial energy, $\sigma_{\text {crysta/glass }}$ is the crystal/glass interfacial energy and critical nucleus size $r^{*}=-2 \sigma_{\text {crystal glass }} / \Delta G_{V}$. The MRO catalysis model has been shown to provide a good representation for Al nanocrystal nucleation during primary crystallization in amorphous $\mathrm{Al}_{88} \mathrm{Y}_{7} \mathrm{Fe}_{5}[36]$.

In addition to the correct accounting for the nucleation behavior, the determination of $\tau$ provides a direct measure for $\beta$, as is shown in Eq. 5,

$$
\tau=\frac{1}{2 Z^{2} \beta}
$$

This method is preferred compared to the commonly used approach of approximately $\beta$ by $\mathrm{D} / a^{2}$ where $\mathrm{D}$ is the diffusivity in the glass that is ill-defined for a multicomponent alloy and a is a jump distance. Moreover, since $\mathrm{D}$ values are often unavailable a further approximation is employed to relate $\mathrm{D}$ to the viscosity, $\eta$ through the Stokes-Einstein relation, $\left(D=\frac{k_{B} T}{6 \pi \eta r}, \mathrm{r}\right.$ is the 
radius of the spherical particle or atom size) but this relation has been shown not to hold near $\mathrm{T}_{\mathrm{g}}$ [37].

There are also several proposed models to explain the ultra-high Al nanocrystal density from primary crystallization in Al-based metallic glasses, including the, "phase separation" and the "quenched-in nuclei" models. The "phase separation" model claims that there is a phase separation step prior to the crystallization, during which the Al-rich and the solute-rich amorphous phases form. Within the "phase separation" model, there still are debates over the origin of phase separation regions, what the size and density of the phase-separated regions are and how the phase-separated regions evolve into stable crystals. The "quenched-in nuclei" model proposes that there are crystal embryos formed in the high temperature liquid or during the rapid quenching, but due to the rapid viscosity increase with decreasing temperature, there is not enough time for them to grow into stable crystals.

\subsection{Phase separation model}

The experimental evidences supporting the "phase separation" model are given by the results from bright field transmission electron microscopy (TEM) imaging [38], X-ray diffraction [39, 40], energy-dispersive X-ray spectroscopy/electron energy loss spectroscopy (EDS/EELS)[41], atom probe tomography (APT) [9, 42, 43], small-angle and wide angle X-ray scattering (SAXS/WAXS) [44-46] and high energy XRD (HEXRD) investigations [9]. For example, the $\mathrm{X}$-ray diffraction pattern of the amorphous $\mathrm{Al}_{87} \mathrm{Ni}_{8} \mathrm{La}_{5}$ alloy annealed at $150{ }^{\circ} \mathrm{C}(78$ degrees lower than $\mathrm{T}_{\mathrm{x}}$ ) for $25 \mathrm{~h}$ shows two diffuse halos from the $\mathrm{Al}$ enriched and $\mathrm{Al}$ depleted amorphous regions [39]. However, the size and density of the phase-separated regions measured by the various methods are inconsistent, resulting in different mechanisms that have been proposed to explain how the phase-separated regions evolve into crystals. The Al-rich regions measured by the BF-TEM were about $50 \mathrm{~nm}$ in diameter for the Al-Gd-La-Ni amorphous alloy [38] while the SAXS/WAXS and EDS/EELS measurements yield a composition fluctuation size sale of about $10 \mathrm{~nm}$ in the $\mathrm{Al}_{85} \mathrm{Ni}_{5} \mathrm{Y}_{6} \mathrm{Fe}_{2} \mathrm{Co}_{2}, \mathrm{Al}_{92} \mathrm{Sm}_{8}$ and $\mathrm{Al}_{91} \mathrm{Gd}_{9}$ amorphous alloys[41, 44, 45]. With such large phase-separated regions, nanocrystals either start to nucleate on the surface [38] or from the center of the Al-rich amorphous phase [46] and the process is accomplished when all of the Al-rich phase regions undergo crystallization. Because the growth of the Al nanocrystals is constrained by the size of Al-rich regions, the size of the Al nanoparticles and the 
Al-rich regions should be approximately identical $(\sim 10 \mathrm{~nm})$. However, the size of the Al-rich region measured by APT for $\mathrm{Al}_{88} \mathrm{Y}_{7} \mathrm{Fe}_{5}$ [42], $\mathrm{Al}_{90} \mathrm{~Tb}_{10}$ [9], $\mathrm{Al}_{89} \mathrm{Ni}_{6} \mathrm{La}_{5}$ [43] amorphous alloys is of a size scale of sub-nanometer or of nanometer and of a high density of $10^{25} / \mathrm{m}^{3}[9,42]$. For an $\mathrm{Al}_{89} \mathrm{Ni}_{6} \mathrm{La}_{5}$ amorphous alloy, after crystallization, $\alpha$-Al particles were almost pure $\mathrm{Al}$ and surrounded by a La rich shell [43]. Actually, in terms of the crystallization reaction the "phase separation" model is consistent with the "quenched-in nuclei" model and supports a nucleation/growth based crystallization process[42], which will be discussed in the section 2.2.

The phase separation model has been applied to explain some of the experimental observations. Regarding to the high nucleation rates and low growth rates, the pure $\mathrm{Al}$ zones appear to catalyze the $\alpha$-Al nucleation, explaining the high nucleation rates and the solute rich regions between the $\mathrm{Al}$ rich regions inhibit the long-range diffusion, explaining the low growth rates [42]. Also, the shift in $T_{g}$ to higher temperatures at higher annealing temperatures could be explained: if the annealing temperature exceeds the $\mathrm{T}_{\mathrm{g}}$ of a particular phase separated region, this region crystallizes and no longer contributes to the observed glass transition and the $T_{g}$ shifts to higher temperature in the subsequent heating run [6]. However, for a phase separation within a miscibility gap, the volume fraction of $\mathrm{Al}$-rich regions and the subsequent nucleation density can decrease with increasing crystallization temperature. In contrast, in the few alloy systems where quantitative nucleation rates have been measured, the rate increases with increasing crystallization temperature [10, 36, 42].

The origin of phase-separation is under debate. On one hand, it is believed that in the Albased amorphous alloys there could exist miscibility gap, which leads to spinodal decomposition induced phase-separation [47]. At the first glance, spinodal decomposition is unlikely to happen, because the liquid Al-TM-RE alloys should be in a region of solute solubility due to the high aluminum content and the negative enthalpies of mixing. However, according to the HumeRothery and Anderson, in binary liquid systems with a strongly negative heat of mixing, a narrow miscibility gap may open near the composition corresponding to maximal atomic packing efficiency due to the rapid dip in the Gibbs free energy curve [48, 49]. Another possibility for the origin of phase separation is the decomposition by compound formation [6]. 


\subsection{Quenched-in nuclei model}

The idea of "quenched-in nuclei" model in Al-based amorphous alloys could be dated back from the 1990s $[15,50-52]$ because the $\mathrm{Al}_{\mathrm{fcc}}$ crystal number density is so high that researchers assumed there must exist "quenched-in nuclei" to catalyze the heterogeneous nucleation [16]. Supporting evidences are given by computer simulation[53], nuclear magnetic resonance (NMR) measurement [33], JMA analysis [32] and fluctuation electron microscopy (FEM) [54, 55]. Computer simulations show that there are fcc clusters of between 40 and $100 \mathrm{Al}$ atoms in an Al-Y binary alloy [53]. The NMR results revealed the existence of quenched-in Al clusters which are indistinguishable from the atomic configuration of atoms in fcc $\alpha$ - $\mathrm{Al}$ in the asspun $\mathrm{Al}_{85} \mathrm{Ni}_{11} \mathrm{Y}_{4}$ amorphous alloy [33]. The local Avrami coefficient $\mathrm{n}(\mathrm{x})$ vs. crystallized fraction relationship shows that $\mathrm{n}(\mathrm{x})$ starts from a value of 1.6, indicating a zero nucleation rate thus growth of pre-existing nuclei [32]. The application of FEM on amorphous $\mathrm{Al}_{92} \mathrm{Sm}_{8}$ and $\mathrm{Al}_{88} \mathrm{Y}_{7} \mathrm{Fe}_{5}$ shows that the rapid quenching of the alloys from the liquid leads to the formation of nanoscale aluminum-like medium range order (MRO), which is consistent with the quenched-in nuclei model of primary crystallization $[54,55]$. Sheng et al. has reported that the MRO development is a process that not only occurs on larger distances but also requires the cooperation of clusters rather than individual atoms. Therefore, the degree and extent of MRO may depend on the cooling rate [56]. The size and the density of the MRO in Al-Y-Fe amorphous alloy are measured to be around $1.8 \mathrm{~nm}$ in diameter with a number density of about $10^{25} / \mathrm{m}^{3}$ [57] and are consistent with the APT measurements for pure Al regions [9, 42]. Therefore, it can be considered that the "quenched-in nuclei" is represented by the MRO measured by FEM and the pure $\mathrm{Al}$ regions measured by APT.

The origin of the "quenched-in nuclei" can be explained by the schematic TTT diagram shown in Fig. 4. Upon quenching the liquid alloy to room temperature, the cooling rate is insufficient to bypass the nucleation onset completely so that some small fraction of crystallites may form initially, but the rapidly rising viscosity and the falling growth rate with continued cooling near $T_{g}$ prevents rapid cluster growth. Upon subsequent devitrification, rapid crystallization due to the development of quenched-in nuclei as well as the additional nucleation ensues at $T_{x}$, which will coincide with $T_{g}$ [58]. However, with the further understanding on MRO, it is believed that the MRO (or "quenched-in nuclei") is a key intrinsic characteristic of 
the amorphous state and is sustained by the glass itself [59]. The isothermal DSC and electrical resistivity traces are characteristic of a nucleation-and-growth transformation [15, 42, 60]. Also, based on the MRO seeded nucleation configuration that Al crystals develop on the core of the MRO spheres, it is possible to apply classical nucleation theory to describe the heterogeneous crystallization behavior of Al nanocrystals [36]. In summary, both of the "phase separation" and "quenched-in nuclei" theories agree that the amorphous Al-based alloys are spatially heterogeneous, which leads to the high nucleation rates of $\mathrm{Al}_{\mathrm{fcc}}$. However, the origin of the heterogeneities and how the heterogeneities develop into the stable crystals are different between the two models.

\section{Minor alloying effects on glass forming ability and crystallization}

The glass-forming ability of the Al-based amorphous alloys is considered as marginal due to the requirement of rapid quenching and partly because the glass-forming composition range lies on the solute-rich side of the eutectic point, where the liquidus temperature rises steeply with solute concentration, resulting in a strongly reduced $\mathrm{T}_{\mathrm{g}}$ [61]. Also, the GFA and crystallization in Al-based metallic glasses are very sensitive to minor alloying. In the Al-Y-Fe system for example (Table 1), the minor element doping can introduce a $100{ }^{\circ} \mathrm{C}$ change in $T_{x}$. Previously, progress has been made in rationalizing the GFA based upon the empirical/semi-empirical rules ("multicomponent alloys", "large radius difference", "negative heat of mixing" and "deep eutectic" guidelines) $[62,63]$. Several parameters have been proposed as the indicators of the GFA, such as the reduced glass transition temperature $T_{r x}\left(=T_{g} / T_{1}\right)$, the width of the supercooled liquid region $\Delta T_{x}\left(=T_{x}-T_{g}\right), T_{1}-T_{g}\left(T_{x}\right)$ and $\gamma=\left[T_{x} /\left(T_{g}+T_{1}\right)\right]$ where $T_{1}$ is the liquidus temperature.

By analyzing the critical cooling rates from $3.0 \times 10^{3} \mathrm{~K} / \mathrm{s}$ to $1.0 \times 10^{4} \mathrm{~K} / \mathrm{s}$ for a series of Al-based amorphous alloys, it was found that the systems with a larger negative value of $\Delta G_{\text {mix }}$ have higher GFA [64]. As another example, the improvement of GFA in $\mathrm{Al}_{86} \mathrm{Ni}_{6} \mathrm{Y}_{6} \mathrm{Ce}_{2}$ compared with the $\mathrm{Al}_{88} \mathrm{Ni}_{6} \mathrm{Y}_{6}$ amorphous alloy is attributed to the increase of the number of the components because the energetic advantage of forming an ordered structure of longer-range periodicity is reduced by the increased complexity and the bigger crystal unit cell [24], but this suggestion has not been proven to be general. While these criteria are still under discussion and are used to explain the experimental results on the Al-based metallic glasses, they offer limited predictive capability. 
In terms of structural characteristics, based on a topological instability model, the " $\lambda$ criterion" $\left(\lambda=\sum_{i=B}^{Z} c_{i}\left|\left(r_{i} / r_{A l}\right)^{3}-1\right|\right.$, where $c_{i}$ is the atomic concentration, $r_{i}$ is the metallic radii), has been proposed for the Al-based metallic glass and the amorphous alloys. Alloy compositions with $\lambda>0.1$ exhibit glassy behavior, whereas nanoglassy alloys occur when $\lambda \approx 0.1$ [65]. Because of the Al-TM "bond shortening" effect from the strong interaction between Al and TM, atoms in alloys cannot always be treated as hard-spheres [66]. In $\mathrm{Al}_{86} \mathrm{Ni}_{7} \mathrm{X}_{1} \mathrm{Y}_{6}(\mathrm{X}: \mathrm{Ag}, \mathrm{Au}, \mathrm{Pt}$ ), a similar "bond shortening" effect is also observed in the Al-X bond [67]. The nominal atomic radii are replaced by the effective atomic radii, resulting in a revised $\lambda$ ' parameter. The $\lambda^{\prime}$ corresponding to the best GFA in each Al-Ni-RE system changes with $\mathrm{r}_{\mathrm{RE}}$ linearly and $\mathrm{T}_{\mathrm{x}}$ as well as $\Delta \mathrm{H}_{\text {mix }}$ linearly increase with $\lambda^{\prime}$ [68]. Also, the increased atomic packing efficiency will lead to an enhancement of GFA. For example, the GFA change with the composition variation was interpreted based on Miracle's model of the atom packing efficiency of the RE-centered clusters in the Al-Ni-La-Gd, Al-Ni-(La-Ce) and Al-Ni-La-(Sc,Dy,Gd,Ce) alloys [69-71]. In addition, a "cluster line method" was proposed to find the optimal compositions for glass formation in the Al-RE-TM ternary metallic glasses to allow each and every Al atom to be shared by both a TMcentered cluster and a RE-centered cluster [72-74]. With the "cluster line method", optimal glass former in Al-RE-TM alloy system was pinpointed by the intersection of the two cluster lines and the composition of lines was determined by the number of nearest neighbors given by the atomic radii of the corresponding elements. This method was found to be useful in preparing the $1 \mathrm{~mm}$ fully glassy rods with the compositions of $\mathrm{Al}_{86} \mathrm{Ni}_{6} \mathrm{Y}_{4.5} \mathrm{Co}_{2} \mathrm{La}_{1.5}, \mathrm{Al}_{86} \mathrm{Ni}_{7} \mathrm{Y}_{5} \mathrm{Co}_{1} \mathrm{La}_{1}$ and $\mathrm{Al}_{86} \mathrm{Ni}_{7} \mathrm{Y}_{4.5} \mathrm{Co}_{1} \mathrm{La}_{1.5}[72,75]$.

From another perspective considering the electronic structure, the composition design for enhanced GFA can follow a route towards $2 \mathrm{~K}_{\mathrm{F}}$ (the diameter of the Fermi sphere) $=\mathrm{K}_{\mathrm{p}}$ (the diameter of the pseudo-Brillouin zone), when the electronic density of states at the Fermi level is minimized [76, 77]. With this guideline, $\mathrm{Al}_{86} \mathrm{Ni}_{6.75} \mathrm{Co}_{2.25} \mathrm{Y}_{3.25} \mathrm{La}_{1.75}$ with a good GFA has been discovered [76]. Also, it is found that the supercooled liquid range in the $\mathrm{Al}_{85} \mathrm{RE}_{8} \mathrm{Ni}_{5} \mathrm{Co}_{2}$ alloys strongly depends upon electronegativity of the RE metal [78].

At the local structure level, icosahedral clusters cannot achieve a global periodic packing and the resulting geometrical frustration will facilitate glass formation. In the Al-Sm system, the large size and the strong d-bonding character of Sm atoms suppress the fcc short-range order 
(FSRO) [79] and the icosahedral short-range order (ISRO) is enhanced in favor of glass formation[80]. In the Al-Fe system, the doping of $\mathrm{Nb}$ can enhance GFA because $\mathrm{Nb}$ is dissolved in the icosahedral Al-Fe clusters and thus stabilizing the icosahedral local symmetry [81]. Also, the doping with $\mathrm{Ce}$ improves GFA because for $\mathrm{Al}_{90} \mathrm{Fe}_{10}$, the modes of $\mathrm{Al}-\mathrm{Fe}$ connection are those of weak interaction: vertex-shared, face-shared and even voids (Fig. 5). However, for the $\mathrm{Al}_{90} \mathrm{Fe}_{5} \mathrm{Ce}_{5}$ glass, the collaboration between clusters is manifested by denser modes of interconnections: face-shared and intercross-shared [82]. In the Al-Cu system, the addition of Y extends the short-range landscape (i.e. SRO) with lower coordination number and better spacefilling ability. Also the Y doping facilitates the dense and flexible packing mode of a hybridized icosahedral- and fcc-like packing in medium range [83]. The improved GFA by doping Ni to the Al-Y-La system is understood through the formation of Ni-centered icosahedron-like polydedra to enhance the spatial connectivity between clusters [84]. Similarly, 1 at.\% Ag addition to the Al$\mathrm{Ni}-\mathrm{Y}$ system enhances GFA because the Ag atoms act as "glue" atoms to tighten the glassy structure [61]. The GFA deteriorates with too much Si doping ( $>0.2$ at.\%) in a Al86NigLa 5 alloy because $\mathrm{Si}$ atoms replace the $\mathrm{Al}$ atoms that coordinate with the $\mathrm{Ni}$ and La solute atoms and the the replaced $\mathrm{Al}$ atoms will aggregate together and evolve into the fcc-Al [85]. Lastly, due to the large negative heats of mixing between TM-Ln atom pairs, a backbone structure consisting of transition metal-lanthanide (TM-Ln) exists in the Al based metallic glasses (Fig. 6), which can reinforce the amorphous structure and benefit the GFA [86]. $\mathrm{T}_{\mathrm{x}}$ shows an increasing tendency with the increase of quenching rate, which is ascribed to the argument that the amount of ridged string-like backbone clusters is larger at a higher quenching rate [87]. While it is evident that several local arrangements have been proposed to influence the GFA in amorphous Al alloys and have been applied to rationalize the GFA in specific cases, a general local structure guideline is still under development.

From the thermodynamic viewpoint, the amorphization driving force, defined as the free energy difference between the solid solution and its amorphous counterpart, was proposed to be positively correlated with the GFA in the Al-Ca-Cu system [88]. With the same strategy of amorphization driving force, $\mathrm{Al}_{74} \mathrm{Cu}_{14} \mathrm{Y}_{12}$ was pinpointed as the optimized composition with the best GFA in the Al-Cu-Y system [89]. Also, a thermodynamic parameter $\theta$ (Eq. 6), defined as the product of the mixing entropy $\Delta S_{m i x}$ and mismatch entropy $S_{\sigma}$, was proposed to evaluate the 
GFA of the amorphous $\mathrm{Al}_{84} \mathrm{Ni}_{10}\left(\mathrm{Ce}_{3} \mathrm{RE}_{3}\right)(\mathrm{RE}=\mathrm{La}, \mathrm{Pr}, \mathrm{Nd}, \mathrm{Gd})$ alloys because there is a positive linear relationship between $\theta$ and $\mathrm{T}_{\mathrm{rx}}[90]$.

$$
\theta=\Delta S_{m i x} \times S_{\sigma} / k_{B}
$$

The fragility parameter $\mathrm{m}$ was proposed by Angell to describe the liquid dynamics which is the slope of the temperature dependence of viscosity $\eta$ at $\mathrm{T}_{\mathrm{g}}$. For Al-based metallic glasses, $\mathrm{m}$ ranges from 57 to 209 [91]. Therefore, the Al-based metallic glasses are considered to be very fragile compared with the bulk glass former Pd-based metallic glasses $(m=50 \sim 73)$ and the oxide glasses $(m=21 \sim 25)$ [92]. A new parameter, $M$, has been further developed which is based on the viscosity variation rate of superheated liquids towards the liquidus temperature $\mathrm{T}_{1}$ (Eq. 7).

$$
M=\left|\frac{\partial \eta(T) / \partial \eta\left(T_{l}\right)}{\left.\partial T / \partial T_{l}\right)}\right|_{T=T_{l}}
$$

The critical cooling rate increases and $T_{x}$ decreases with increasing $M$ in the Al-based metallic glasses [93, 94]. A refined parameter combining both thermodynamic and the liquid dynamic factors $\theta / \mathrm{M}$ has a slightly improved proportional correlation with GFA [90]. Also, $\alpha_{\exp } / T_{\mathrm{L}}\left(\alpha_{\exp }\right.$ : average linear thermal expansion coefficient) has a positive correlation with $\mathrm{T}_{\mathrm{rx}}$ in Al-based amorphous alloys [95] and it was concluded that the amorphous alloy which exhibits better GFA contains less free volume [96].

Kinetic factors are also closely related with the GFA. Wang et al. suggest that the Al-RE glass formers, which have hypereutectic compositions where one of the phases in the eutectic is a compound phase, can exhibit a large non-equilibrium undercooling because when the phase growth occurs via the motion of steps, it is generally sluggish for faceted crystals or for complex compounds [97]. Also, the variation of $\mathrm{T}_{\mathrm{x}}$ in the Al-Y-Fe system with $\mathrm{Cu}$ doping is believed to be related with the transport behavior change, which is exhibited as the delay time change during the transient stage of the nucleation $[36,98]$. There is an increase in $\mathrm{T}_{\mathrm{g}}$ with microalloying of TM to Al-Y-Fe alloys because of the decreased atomic mobility [99].

All of the above GFA metrics are for minor alloying of soluble element with a negative heat of mixing. However, for when an insoluble element such as $\mathrm{Pb}$ with positive heat of mixing is included in Al-TM-RE systems, upon rapid solidification, the phase separated Al-rich and $\mathrm{Pb}$ 
regions solidify into the Al-based amorphous matrix and spherical crystalline $\mathrm{Pb}$ particles. The $\mathrm{Pb}$ particles can serve as the nucleation sites for $\mathrm{Al}$ nanocrystals and promote crystallization, thus decreasing $T_{x}$ (Table 1). For In doping, the catalytic mechanism is complicated due to the fact that $\mathrm{Al}$ nucleates on the interface between the liquid In and the amorphous matrix. However, the coherent interface in the HR STEM image showed a good contacting behavior between $\mathrm{Al}$ and In [100].

As the experimental evidence for the role of minor alloying on the GFA and crystallization behavior in amorphous $\mathrm{Al}$ alloys increases, it is evident that the effects are significant. Some trends are developing for specific additions and substitutions, but a mechanistic understanding is incomplete.

\section{Summary and outlook}

The understanding of the crystallization behaviors and glass forming ability of the Albased amorphous alloys is of great interest and importance because the superior mechanical properties could be further enhanced by microstructure optimization through the controlled primary crystallization of Al nanoparticles and the improved GFA can further broaden the field of application. For the crystallization behavior the two main models based upon phase separation and quenched-in nuclei differ in the origin of the precursor Al-rich regions, but both models agree that the as-quenched Al-based metallic glasses are spatially heterogeneous, which accounts for the high nucleation rate and high $\mathrm{Al}_{\mathrm{fcc}}$ nanocrystal density. In fact, recent structural investigation has identified the Al-rich regions as MRO that appears to be an inherent structural characteristic in amorphous Al alloys. Minor element doping plays an important role in tuning the GFA and influencing the crystallization behavior. A variety of guidelines and structural arguments have been proposed to account for GFA and minor alloying effects for specific cases, but a general widely applicable criterion is not available yet.

Even though there have been significant advances recently, there are still challenges to the understanding of primary crystallization to overcome in the future, including the complete modeling of the growth and coarsening. There are several criterion for glass forming ability for different specific system of Al-based amorphous alloys. However, there is no general rules that can be used to predict the GFA for broader range of Al-based amorphous alloys. 


\section{Acknowledgement}

The financial support from ONR (N00014-12-1-0569) and NSF (DMR 1332851) is gratefully acknowledged.

\section{Figures and Table}

\begin{tabular}{|c|c|c|c|c|c|}
\hline Composition & $\mathbf{T}_{\mathbf{x}}\left({ }^{\circ} \mathbf{C}\right)$ & Reference & Composition & $\mathbf{T}_{\mathbf{x}}\left({ }^{\circ} \mathbf{C}\right)$ & Reference \\
\hline $\mathrm{Al}_{88} \mathrm{Y}_{7} \mathrm{Fe}_{5}$ & 267 & {$[100]$} & $\mathrm{Al}_{88} \mathrm{Y}_{7} \mathrm{Fe}_{4} \mathrm{Ni}$ & 240 & {$[101]$} \\
\hline $\mathrm{Al}_{87} \mathrm{Y}_{7} \mathrm{Fe}_{5} \mathrm{~Pb}$ & 247 & {$[100]$} & $\mathrm{Al}_{88} \mathrm{Y}_{7} \mathrm{Fe}_{2} \mathrm{Ni}_{3}$ & 210 & {$[101]$} \\
\hline $\mathrm{Al}_{87.5} \mathrm{Y}_{7} \mathrm{Fe}_{5} \mathrm{In}_{0.5}$ & 232 & {$[100]$} & $\mathrm{Al}_{88} \mathrm{Y}_{6} \mathrm{Fe}_{5} \mathrm{Cu}$ & 221 & {$[36]$} \\
\hline $\mathrm{Al}_{87} \mathrm{Y}_{7} \mathrm{Fe}_{5} \mathrm{In}$ & 229 & {$[100]$} & $\mathrm{Al}_{88} \mathrm{Y}_{7} \mathrm{Fe}_{4} \mathrm{Cu}$ & 222 & {$[55]$} \\
\hline $\mathrm{Al}_{86.5} \mathrm{Y}_{7} \mathrm{Fe}_{5} \mathrm{In}_{1.5}$ & 223 & {$[100]$} & $\mathrm{Al}_{88} \mathrm{Y}_{7} \mathrm{Fe}_{4.5} \mathrm{Cu}_{0.5}$ & 247 & {$[55]$} \\
\hline $\mathrm{Al}_{86} \mathrm{Y}_{7} \mathrm{Fe}_{5} \mathrm{In}_{2}$ & 220 & {$[100]$} & $\mathrm{Al}_{87} \mathrm{Y}_{7} \mathrm{Fe}_{5} \mathrm{Cu}$ & 278 & {$[55]$} \\
\hline $\mathrm{Al}_{87} \mathrm{Y}_{7} \mathrm{Fe}_{5} \mathrm{Ni}$ & 283 & {$[101]$} & $\mathrm{Al}_{87.5} \mathrm{Fe}_{5} \mathrm{Y}_{7} \mathrm{Ti}_{0.5}$ & 310 & {$[99]$} \\
\hline
\end{tabular}

Table 1 A summary for the $T_{x}$ for the primary crystallization in the Al-Y-Fe system with minor element doping. 


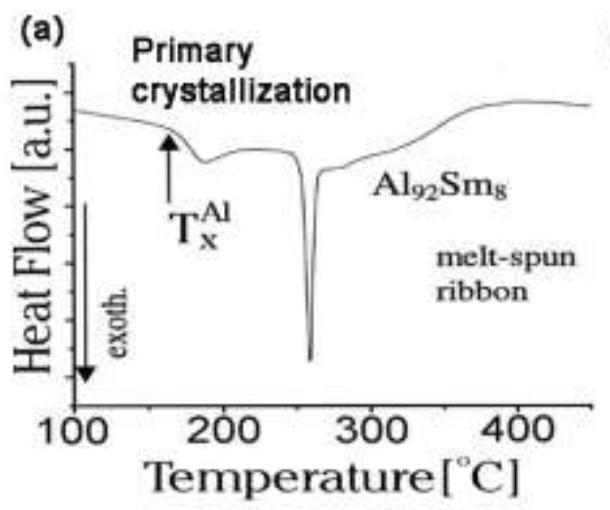

(b)

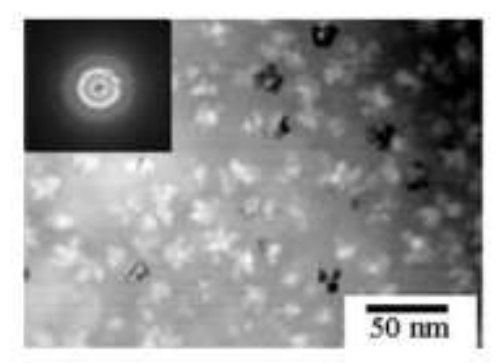

$\mathrm{Al}_{92} \mathrm{Sm}_{8} 150^{\circ} \mathrm{C}$ for $600 \mathrm{~s}$

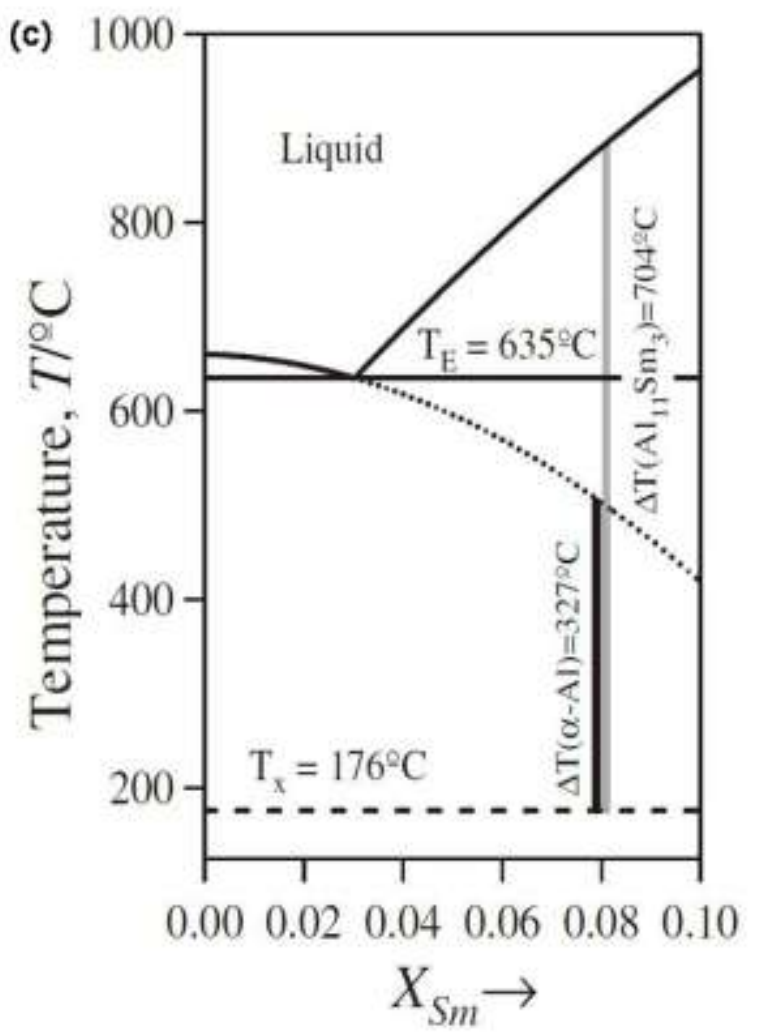

Fig. 1 (a) Continuous DSC heating trace for $\mathrm{Al}_{92} \mathrm{Sm}_{8}$ at $20 \mathrm{~K} / \mathrm{min}$. (b) TEM bright field image for $\mathrm{Al}_{92} \mathrm{Sm}_{8}$ annealed at $150^{\circ} \mathrm{C}$ for $600 \mathrm{~s}$. (c) Al-Sm phase diagram on the $\mathrm{Al}$ rich side. 


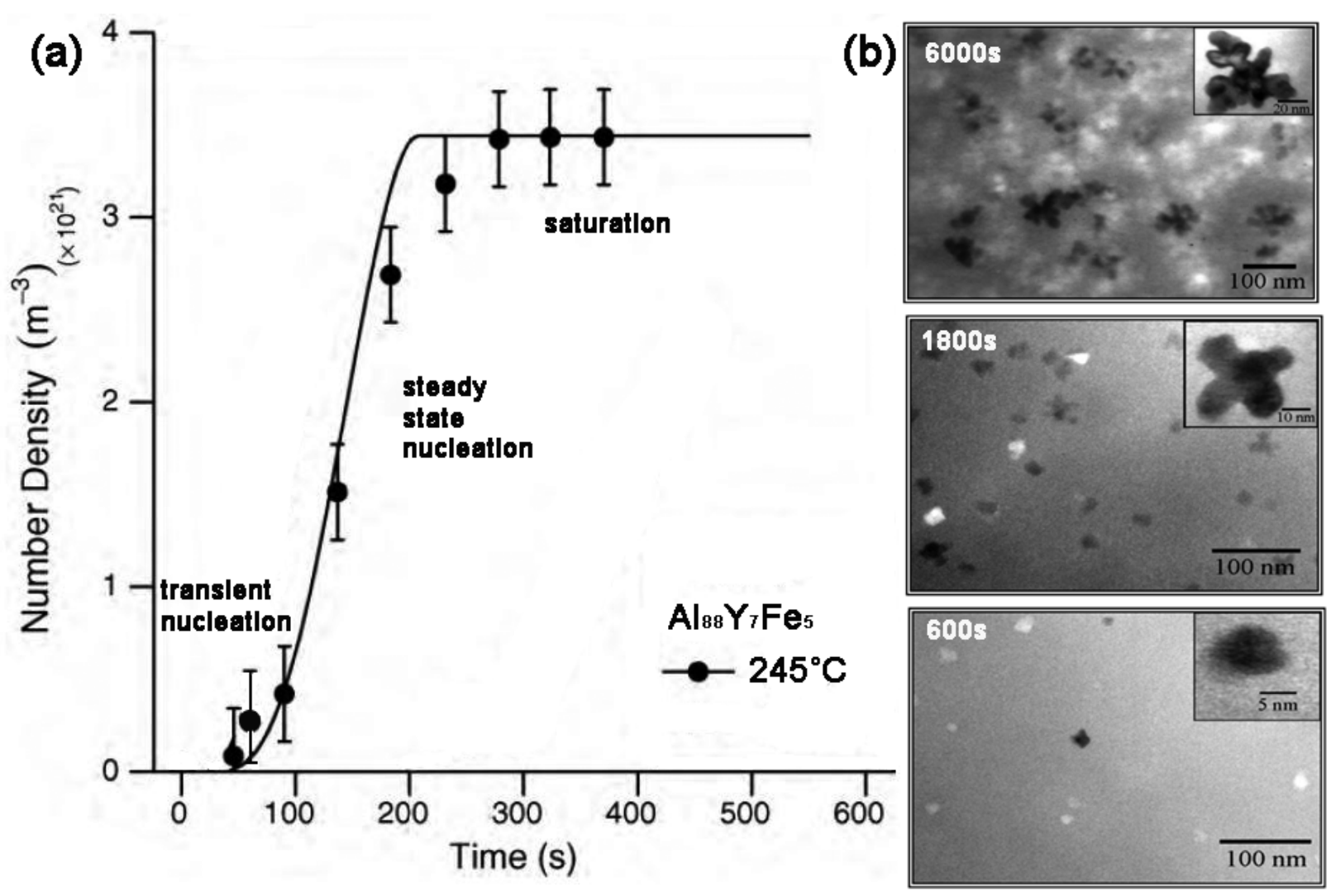

Fig. 2 (a) Al nanocrystal number density vs. annealing time plot for $\mathrm{Al}_{88} \mathrm{Y}_{7} \mathrm{Fe}_{5}$ annealed at $245^{\circ} \mathrm{C}$. (b) Corresponding TEM bright field images for $\mathrm{Al}_{88} \mathrm{Y}_{7} \mathrm{Fe}_{5}$ with annealing time of $600 \mathrm{~s}$, $1800 \mathrm{~s}$ and $6000 \mathrm{~s}$. 
(a)
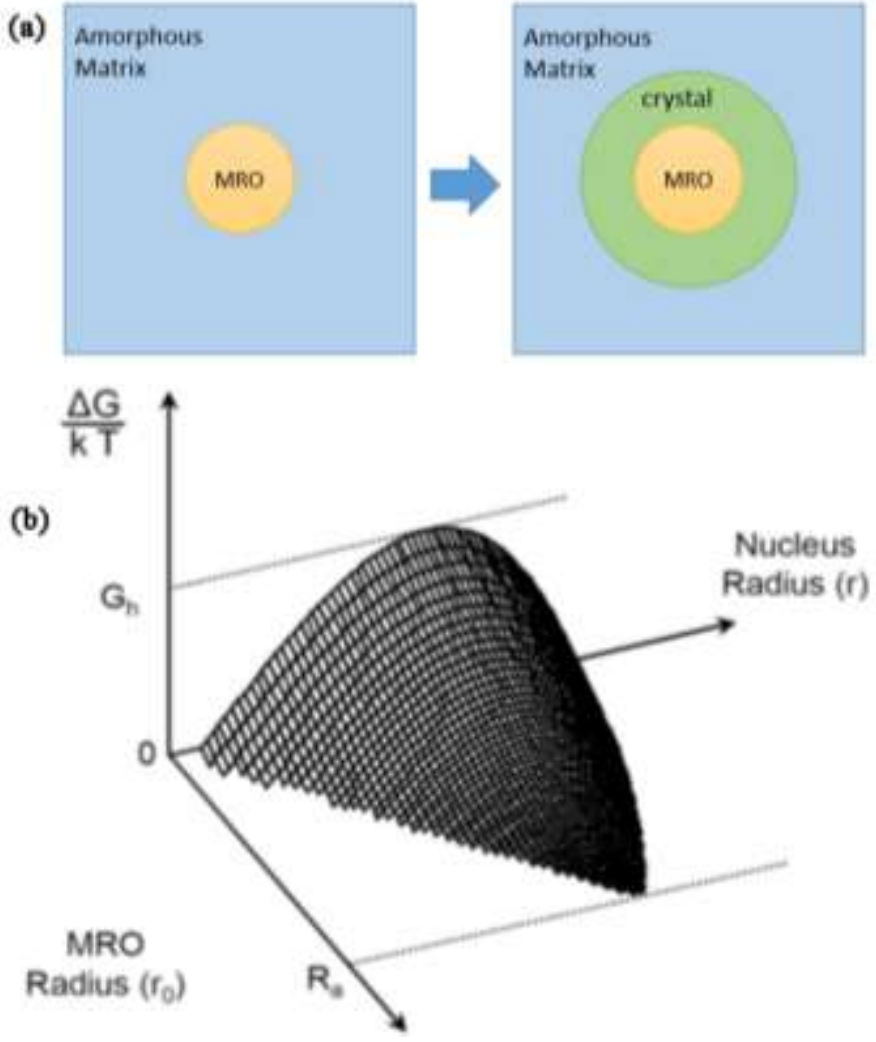

Fig. 3 (a) Configuration for the MRO seeded nucleation in $\mathrm{Al}_{88} \mathrm{Y}_{7} \mathrm{Fe}_{5}$ amorphous alloy and MRO are Al-like clusters. (b) Schematic plot of $\Delta \mathrm{G}\left(\mathrm{r}, \mathrm{r}_{\mathrm{o}}\right) / \mathrm{kT}$ relationship with MRO radius $\mathrm{r}_{\mathrm{o}}$ and nucleus radius $r$. 
Nucleation control
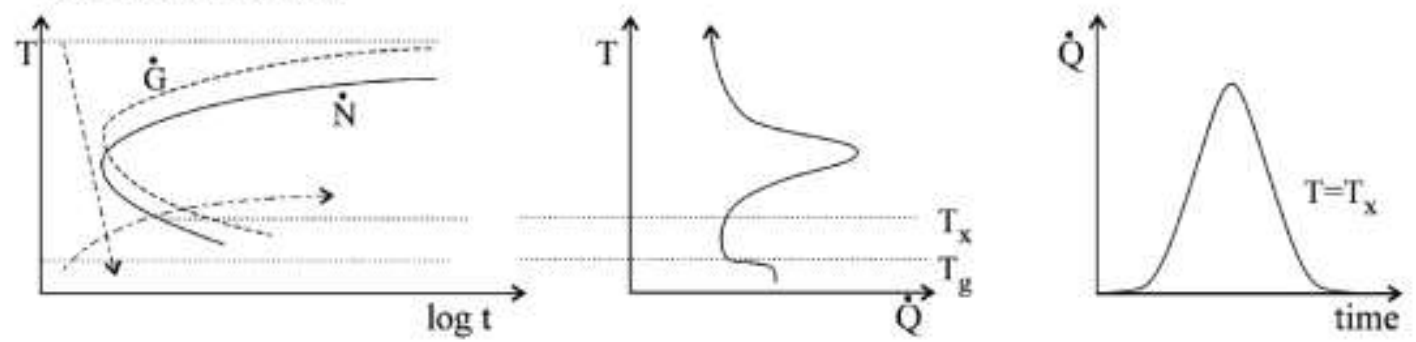

Growth control
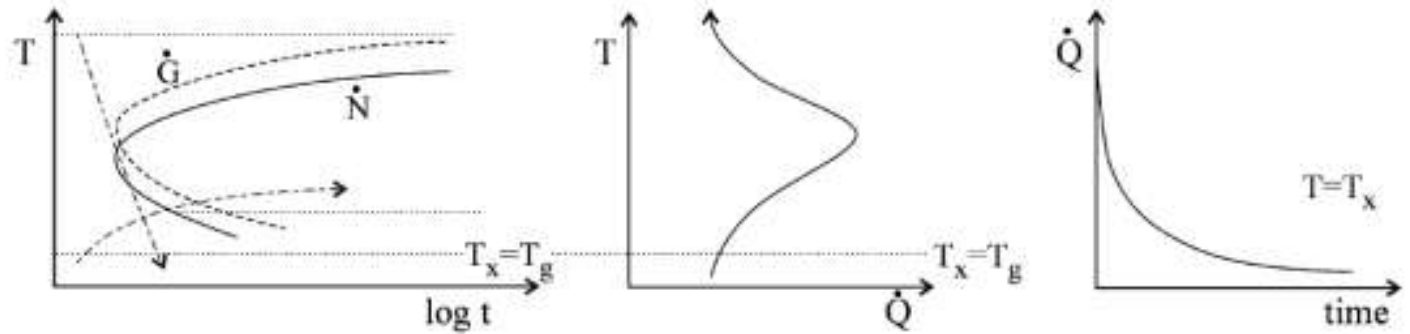

Fig. 4 Schematics showing kinetics of metallic glass formation: nucleation control vs. growth control. Quenching and reheating paths are shown on the TTT diagram and thermograms $(\mathrm{dQ}=\mathrm{dt}$ : heat evolution rate). Reproduced from reference [11] with permission from Elsevier. 


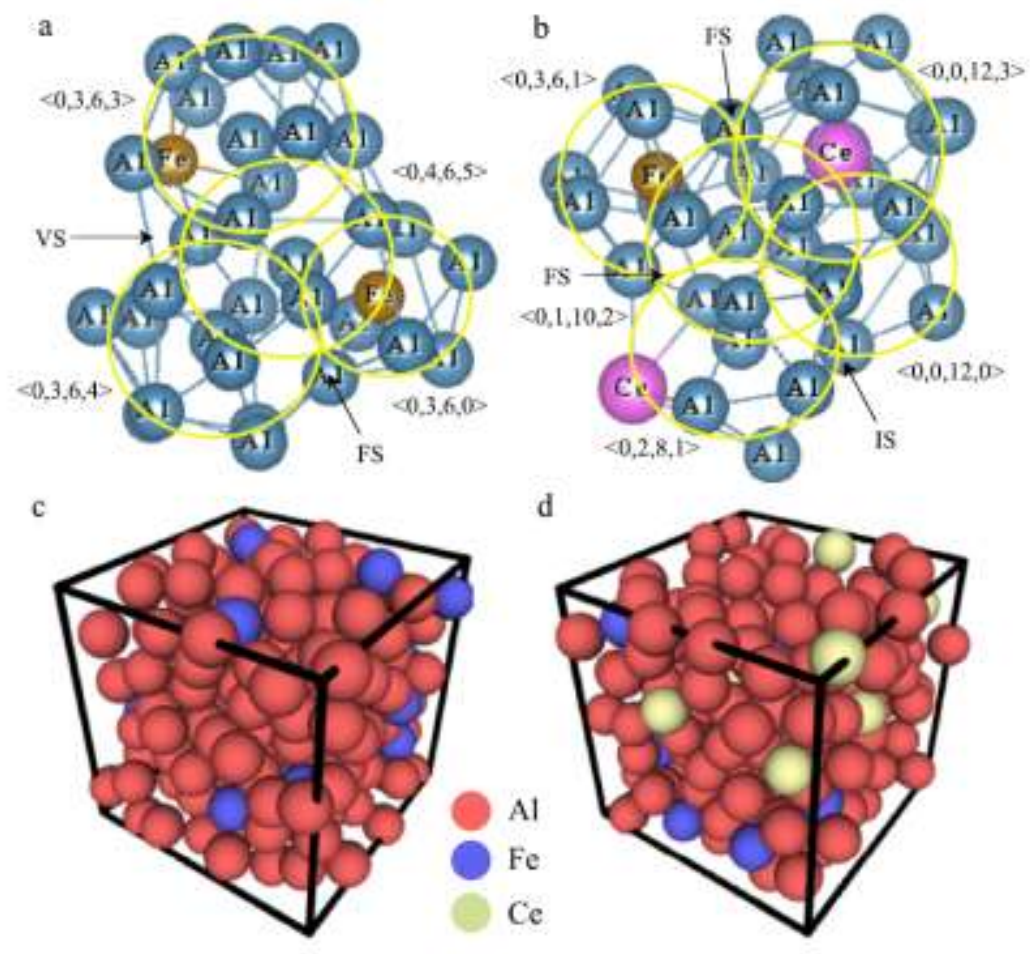

Fig. 5 Icosahedral MRO referring to the $\mathrm{Al}$ atoms, $\mathrm{Fe}$ atoms and $\mathrm{Ce}$ atoms for (a) $\mathrm{Al}_{90} \mathrm{Fe}_{10}$ and (b) $\mathrm{Al}_{90} \mathrm{Fe}_{5} \mathrm{Ce}_{5}$ glasses. The central atoms are presented without bonds. The icosahedra are linked by vertex-shared (VS), face-shared (FS), and intercross-shared (IS) atoms. Reproduced from reference [82] with permission with Elsevier.

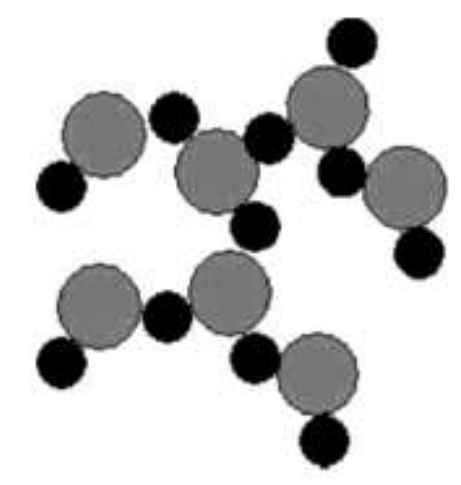
$\mathrm{Zr}-\mathrm{B} @ \mathrm{Fe}_{70} \mathrm{Zr}_{10} \mathrm{~B}_{20}$
Ln-B@ $\mathrm{Fe}_{76} \mathrm{Ln}_{4} \mathrm{~B}_{20}$
$\mathrm{Y}-\mathrm{Cu}$ @ $\mathrm{Mg}_{60} \mathrm{Y}_{10} \mathrm{Cu}_{30}$
Ln-TM@ $\mathbf{A l}_{85} \mathrm{Ln}_{7} \mathrm{TM}_{8}$

Fig. 6 Sketch of atomistic network/backbone formed by the large atoms and small atoms. Several metallic glasses are listed and their network components are indicated. Reproduced from reference [86] with permission from Elsevier. 


\section{References}

[1] A. Inoue, K. Ohtera, A.P.Tsai, T. Masumoto, Jpn. J. Appl. Phys., 27 (1988) L479.

[2] Y. He, S.J. Poon, G.J. Shiflet, Science, 241 (1988) 1640-1642.

[3] G. Wilde, H. Sieber, J.H. Perepezko, Scr. Mater., 40 (1999) 779-783.

[4] X. Wang, D. Wang, B. Zhu, Y. Li, F. Han, J. Non-Cryst. Solids, 385 (2014) 111-116.

[5] R.I. Wu, G. Wilde, J.H. Perepezko, Mater. Sci. Eng. A, 301 (2001) 12-17.

[6] J. Bokeloh, N. Boucharat, H. Rösner, G. Wilde, Acta Mater., 58 (2010) 3919-3926.

[7] F.Q. Meng, J. Geng, M.F. Besser, M.J. Kramer, R.T. Ott, J. Appl. Phys., 116 (2014) 223505.

[8] K.L. Sahoo, R. Sahu, J. Non-Cryst. Solids, 365 (2013) 33-36.

[9] Y.E. Kalay, I. Kalay, J. Hwang, P.M. Voyles, M.J. Kramer, Acta Mater., 60 (2012) 994-

1003.

[10] J.H. Perepezko, S.D. Imhoff, J. Alloys Compd., 504, Supplement 1 (2010) S222-S225.

[11] J.H. Perepezko, R.J. Hebert, W.S. Tong, Intermetallics, 10 (2002) 1079-1088.

[12] M.J. Styles, W.W. Sun, D.R. East, J.A. Kimpton, M.A. Gibson, C.R. Hutchinson, Acta Mater., 117 (2016) 170-187.

[13] K.L. Sahoo, R. Sahu, A. Mitra, Mater. Manuf. Processes, 22 (2007) 497-501.

[14] V. Sidorov, P. Svec, D. Janickovic, V. Mikhailov, L. Son, J. Magn. Magn. Mater., 395

(2015) 324-328.

[15] A.P. Tsai, T. Kamiyama, Y. Kawamura, A. Inoue, T. Masumoto, Acta Mater., 45 (1997) $1477-1487$.

[16] Y.E. Kalay, L.S. Chumbley, I.E. Anderson, J. Non-Cryst. Solids, 354 (2008) 3040-3048.

[17] D.V. Louzguine, A. Inoue, J. Mater. Res., 17 (2002) 1014-1018.

[18] A. Anghelus, M.-N. Avettand-Fènoël, C. Cordier, R. Taillard, J. Alloys Compd., 651 (2015) 454-464.

[19] D. Singh, D. Singh, R.K. Mandal, O.N. Srivastava, R.S. Tiwari, J. Alloys Compd., 687 (2016) 990-998.

[20] M. Mansouri, A. Simchi, N. Varahram, E.S. Park, Mater. Sci. Eng.A, 604 (2014) 92-97.

[21] L. Wang, L. Ma, H. Kimura, A. Inoue, Mater. Lett., 52 (2002) 47-52.

[22] D. Kan, X. Li, B. Yang, H. Yang, J. Wang, J. Mater. Sci. Technol., 31 (2015) 489-492.

[23] A. Inoue, F. Kong, S. Zhu, C.T. Liu, F. Al-Marzouki, Mater. Res., 18 (2015) 1414-1425.

[24] M. Salehi, S.G. Shabestari, S.M.A. Boutorabi, Mater. Sci. Eng. A, 586 (2013) 407-412.

[25] S.D. Zhang, Z.M. Wang, X.C. Chang, W.L. Hou, J.Q. Wang, Corros. Sci., 53 (2011) 30073015.

[26] G. Wilde, H. Rösner, Appl. Phys. Lett., 98 (2011) 251904.

[27] G. Abrosimova, A. Aronin, O. Barkalov, D. Matveev, O. Rybchenko, V. Maslov, V. Tkach, Phys. Solid State, 53 (2011) 229-233.

[28] E. Pershina, G. Abrosimova, A. Aronin, D. Matveev, V. Tkatch, Mater. Lett., 134 (2014) 60-63.

[29] W.H. Jiang, M. Atzmon, Acta Mater., 51 (2003) 4095-4105.

[30] Y. Wang, Y. Liu, Y. Li, B. An, G. Cao, S. Jin, Y. Sun, W. Wang, J. Mater. Sci. Technol., 30 (2014) 1262-1270.

[31] Y. Huang, B. Zhou, H. Fan, Y. Wang, D. Wang, J. Sun, J. Shen, Mater. Des. (1980-2015), 62 (2014) 133-136.

[32] T. Demirtaş, Y.E. Kalay, J. Non-Cryst. Solids, 378 (2013) 71-78. 
[33] M.D.H. Lay, A.J. Hill, P.G. Saksida, M.A. Gibson, T.J. Bastow, Acta Mater., 60 (2012) 7988.

[34] D.V. Louzguine, A. Inoue, J. Non-Cryst. Solids, 311 (2002) 281-293.

[35] J.W.P. Schmelzer, A.R. Gokhman, V.M. Fokin, J. Colloid Interface Sci., 272 (2004) 109-

133.

[36] Y. Shen, S. D. Imhoff, J. H. Perepezko, F. Yi, P. M. Voyles, to be published, (2017).

[37] G. Tarjus, D. Kivelson, J. Chem. Phys. , 103 (1995) 3071-3073.

[38] A.K. Gangopadhyay, T.K. Croat, K.F. Kelton, Acta Mater., 48 (2000) 4035-4043.

[39] G.E. Abrosimova, A.S. Aronin, O.I. Barkalov, M.M. Dement'eva, Phys. Solid State, 55

(2013) 1773-1778.

[40] G.E. Abrosimova, A.S. Aronin, O.I. Barkalov, M.M. Dement'eva, Formation of the nanostructure in amorphous alloys of the Al-Ni-Y system, Physics of the Solid State, 55 (2013) 1773-1778.

[41] Y.B. Wang, H.W. Yang, B.B. Sun, B. Wu, J.Q. Wang, M.L. Sui, E. Ma, Evidence of phase separation correlated with nanocrystallization in A185Ni5Y6Fe2Co2 metallic glass, Scripta Materialia, 55 (2006) 469-472.

[42] K.K. Sahu, N.A. Mauro, L. Longstreth-Spoor, D. Saha, Z. Nussinov, M.K. Miller, K.F. Kelton, Acta Mater., 58 (2010) 4199-4206.

[43] B. Radiguet, D. Blavette, N. Wanderka, J. Banhart, K.L. Sahoo, Appl. Phys. Lett., 92 (2008) 103126.

[44] J. Antonowicz, A.R. Yavari, W.J. Botta, P. Panine, Philos. Mag., 86 (2006) 4235-4242.

[45] J. Antonowicz, E. Jezierska, M. Kêdzierski, A.R. Yavari, L. Greer, P. Panine, M. Sztucki, Rev. Adv. Mater. Sci, 18 (2008) 454-458.

[46] J. Antonowicz, M. Kędzierski, E. Jezierska, J. Latuch, A.R. Yavari, L. Greer, P. Panine, M. Sztucki, Small-angle X-ray scattering from phase-separating amorphous metallic alloys undergoing nanocrystallization, Journal of Alloys and Compounds, 483 (2009) 116-119.

[47] J. Antonowicz, J. Mater. Sci., 45 (2010) 5040-5044.

[48] D.H. Kim, W.T. Kim, E.S. Park, N. Mattern, J. Eckert, Prog. Mater. Sci., 58 (2013) 1103-

1172.

[49] W. Hume-Rothery, E. Anderson, Philos. Mag., 5 (1960) 383-405.

[50] M. Blank-Bewersdorff, J. Mater. Sci. Lett., 10 (1991) 1225-1227.

[51] J.C. Foley, D.R. Allen, J.H. Perepezko, Scr. Mater., 35 (1996) 655-660.

[52] D.R. Allen, J.C. Foley, J.H. Perepezko, Acta Mater., 46 (1998) 431-440.

[53] J.E. Spowart, D.B. Miracle, H.M. Mullens, J. Non-Cryst. Solids, 336 (2004) 202-211.

[54] W.G. Stratton, J. Hamann, J.H. Perepezko, P.M. Voyles, X. Mao, S.V. Khare, Appl. Phys.

Lett., 86 (2005) 141910-141910.

[55] W.G. Stratton, J. Hamann, J.H. Perepezko, P.M. Voyles, Intermetallics, 14 (2006) 10611065.

[56] H.W. Sheng, Y.Q. Cheng, P.L. Lee, S.D. Shastri, E. Ma, Acta Mater., 56 (2008) 6264-6272.

[57] F. Yi, Ph.D thesis, The University of Wisconsin - Madison, (2011)

[58] J.H. Perepezko, Prog. Mater. Sci., 49 (2004) 263-284.

[59] Z. Kovács, P. Henits, L.K. Varga, E. Schafler, Á. Révész, J. Alloys Compd., 561 (2013) 59.

[60] L.Q. Xing, A. Mukhopadhyay, W.E. Buhro, K.F. Kelton, Philos. Mag., 84 (2004) 293-302.

[61] Y. Liu, J. Wang, J. Qin, G. Schumacher, Phys. Chem. Liq., 54 (2016) 98-109.

[62] W.L. Johnson, MRS bulletin, 24 (1999) 42-56. 
[63] A. Inoue, A. Takeuchi, Mater. Trans., 43 (2002) 1892-1906.

[64] H.Y. Hsieh, T. Egami, Y. He, S.J. Poon, G.J. Shiflet, J. Non-Cryst. Solids, 135 (1991) 248254.

[65] R.D. Sá Lisboa, C. Bolfarini, W.J. Botta F., C.S. Kiminami, Appl. Phys. Lett., 86 (2005) 211904.

[66] H.Y. Hsieh, T. Egami, Y. He, S.J. Poon, G.J. Shiflet, J. Non-Cryst. Solids, 135 (1991) 248254.

[67] Y. Liu, G. Schumacher, X.F. Bian, J. Banhart, J. Non-Cryst. Solids, 422 (2015) 26-31.

[68] Z. Zhang, X.Z. Xiong, W. Zhou, X. Lin, A. Inoue, J.F. Li, Intermetallics, 42 (2013) 23-31.

[69] J.J. Yi, W. Xu, X.Z. Xiong, L.T. Kong, M. Ferry, J.F. Li, J. Alloys Compd., 628 (2015) 245-250.

[70] Z. Zhang, X.Z. Xiong, W. Zhou, J.F. Li, J. Alloys Compd., 576 (2013) 181-186.

[71] Z. Zhang, Xian-zhong. Xiong, Jiao-jiao. Yi, Jin-fu. Li, J. Non-Cryst. Solids, 369 (2013) 1-4.

[72] B. Yang, J. Yao, Y. Chao, J. Wang, E. Ma, Philos. Mag., 90 (2010) 3215-3231.

[73] C. Dong, J. Qiang, Y. Wang, N. Jiang, J. Wu, P. Thiel, Philos. Mag., 86 (2006) 263-274.

[74] Y. Cheng, E. Ma, Prog. Mater. Sci., 56 (2011) 379-473.

[75] B.J. Yang, J.H. Yao, J. Zhang, H.W. Yang, J.Q. Wang, E. Ma, Scr. Mater., 61 (2009) $423-$ 426.

[76] N.C. Wu, L. Zuo, J.Q. Wang, E. Ma, Acta Mater., 108 (2016) 143-151.

[77] N.C. Wu, D. Kan, L. Zuo, J.Q. Wang, Intermetallics, 39 (2013) 1-4.

[78] D.V. Louzguine, A. Inoue, Appl. Phys. Lett., 79 (2001) 3410-3412.

[79] X.W. Fang, C.Z. Wang, Y.X. Yao, Z.J. Ding, K.M. Ho, Phys. Rev. B, 83 (2011) 224203.

[80] G.B. Bokas, L. Zhao, J.H. Perepezko, I. Szlufarska, Scr. Mater., 124 (2016) 99-102.

[81] F. Audebert, M. Galano, F. Saporiti, J. Alloys Compd., 615, Supplement 1 (2014) S621S626.

[82] J. Han, W.Y. Wang, C. Wang, X. Hui, X. Liu, Zi-Kui. Liu, Intermetallics, 46 (2014) 29-39.

[83] Q. Wang, J. Li, J. Liu, B. Liu, J. Chem. Phys. B, 118 (2014) 4442-4449.

[84] X.M. Shi, X.D. Wang, Q. Yu, Q.P. Cao, D.X. Zhang, J. Zhang, T.D. Hu, L.H. Lai, H.L. Xie, T.Q. Xiao, J.Z. Jiang, J. Appl. Phys., 119 (2016) 114904.

[85] J. Yi, W. Xu, X. Xiong, L. Kong, M. Ferry, J. Li, Adv. Eng. Mater., 18 (2016) 972-977.

[86] S.J. Poon, G.J. Shiflet, F.Q. Guo, V. Ponnambalam, J. Non-Cryst. Solids, 317 (2003) 1-9.

[87] Y. Liu, S.L. Ye, B. An, Y.G. Wang, Y.J. Li, L.C. Zhang, W.M. Wang, J. Alloys Compd., 587 (2014) 59-65.

[88] S. Zhao, J.H. Li, Q. Wang, B.X. Liu, J. Mater. Sci., 51 (2016) 6600-6606.

[89] Q. Wang, J. Li, J. Liu, B. Liu, Metals, 4 (2014) 519-529.

[90] X. Hu, J. Guo, G. Fan, T. Feng, J. Alloys Compd., 574 (2013) 18-21.

[91] P.Y. Cai, J. Sun, X. Bian, Y. Bai, Procedia Eng., 16 (2011) 755-762.

[92] O.N. Senkov, Phys. Rev. B, 76 (2007) 104202.

[93] X.F. Bian, B.A. Sun, L.N. Hu, Y.B. Jia, Phys. Rev. A, 335 (2005) 61-67.

[94] J. Guo, X. Hu, J. Liu, T. Feng, E.Y. Yoon, H.S. Kim, Arch. Metall. Mater., 2015, pp. 1543.

[95] G.H. Li, W.M. Wang, X.F. Bian, J.T. Zhang, R. Li, J.Y. Qin, Mater. Chem. Phys., 116 (2009) 72-75.

[96] G.H. Li, W.M. Wang, X.F. Bian, J.T. Zhang, R. Li, L. Wang, J. Alloys Compd., 478 (2009) 745-749.

[97] N. Wang, Y.E. Kalay, R. Trivedi, Acta Mater., 59 (2011) 6604-6619.

[98] J.H. Perepezko, S.D. Imhoff, R.J. Hebert, J. Alloys Compd., 495 (2010) 360-364. 
[99] K.S. Bondi, A.K. Gangopadhyay, Z. Marine, T.H. Kim, A. Mukhopadhyay, A.I. Goldman, W.E. Buhro, K.F. Kelton, J. Non-Cryst. Solids, 353 (2007) 4723-4731.

[100] Y. Shen, J. Perepezko, J. Non-Cryst. Solids, 643 (2015) S260-S264.

[101] S.D. Imhoff, Ph.D thesis, The University of Wisconsin - Madison (2010) 